\title{
O QUE REVELAM AS PESQUISAS SOBRE AS CLASSES MULTISSERIADAS NOS ANOS INICIAIS DO ENSINO FUNDAMENTAL DA EJA?
}

\author{
WHAT DOES THE RESEARCH REVEAL ABOUT THE MULTISSERIATED CLASSES \\ IN THE INITIAL YEARS OF EJA FUNDAMENTAL TEACHING?
}

\author{
Ada Guimarães Ribeiro'; Regina Magna Bonifácio De Araújo¹ \\ 1 Universidade Federal de Ouro Preto, Instituto de Ciências Sociais e Humanas, ICHS, Rua do \\ Seminário, s/n - Centro. Cep.34420-000 - Mariana - MG - Brasil, ada.guimaraes@yahoo.com.br; \\ regina.magna@hotmail.com.
}

\author{
ART ICLE INFO \\ Article history: \\ Received 2018-11-27 \\ Accepted 2019-06-17 \\ Available online 2019-06-17
}

Palavras-chave: Educação de Jovens e Adultos. Classes Multisseriadas. Estado do Conhecimento.

Keywords: Young people and Adult Education. Multiseriated classes. Knowledge State.

RESUMO: Este trabalho traz como objeto de estudo as Classes Multisseriadas na Educação de Jovens e Adultos. A Educação de Jovens e Adultos- EJA, é uma modalidade de ensino ainda hoje, alvo de intensas pesquisas e indagações no cenário educacional brasileiro. O objetivo desta investigação é apresentar as pesquisas educacionais desenvolvidas sobre o objeto de estudo acima citado, para assim, traçarmos um panorama do que já foi produzido sobre a temática, fazendo em seguida uma seleção das pesquisas realizadas entre os anos de 2010 a 2017 no país. Pretendemos com este estudo, apresentar parte do referencial teórico utilizado para fundamentar as bases da pesquisa de Mestrado, intitulada A prática docente na EJA multisseriada no programa de Pós-Graduação/ Mestrado em Educação da Universidade Federal de Ouro Preto-MG. A pesquisa procura investigar como se dá o processo de ensino em Classes Multisseriadas nos anos iniciais do Ensino Fundamental da EJA, mostrando o quão se faz importante refletir e revelar o papel docente nos contextos escolares pesquisados afim de compreender o cotidiano escolar desta modalidade de ensino. Foi realizado um estudo do tipo Estado do Conhecimento, onde foi possível verificar um número reduzido de trabalhos que abordam a temática.

ABSTRACT: This Job brings as object of study the Multiseriated Classes in the Education of Young people and Adults. The Education of Young and Adults - EJA, is still a modality of education today, object of intense researches and discussions in the Brazilian educational scene. The objective of this research is to present the educational researches developed about the object of study mentioned, so as to draw a panorama of what has been produced about the subject, making next a selection of the researches carried out between the years 2010 and 2017 in the country. Based on this study, present part of the theoretical framework used to support the bases of Master's research, entitled The teaching practice in the multiseriated, in the Graduate Program / Masters in Education of the Federal University of Ouro Preto- MG. The research seeks to investigate how the teaching process occurs in Multiseriated Classes in the initial years of EJA's Elementary School, showing how important it is to reflect and reveal the teaching role in the researched school contexts in order to understand more about the daily school life of this modality teaching. A study of the Knowledge State type was accomplished, being possible to verify a reduced number of works that discuss the theme. 


\section{Introdução}

A EJA, Educação de Jovens e Adultos, hoje, é uma modalidade da educação básica no Brasil, amparada constitucionalmente e legalmente nos vieses das políticas públicas educacionais brasileiras. Tomada por suas especificidades, ela se configura sobre diferentes olhares, buscando suprir necessidades históricas mantidas pelo próprio sistema educacional, com suas raízes de desigualdade e de exclusão. Trata-se de uma modalidade com características próprias, metodologias, planejamentos e atividades específicas, constituída por processos de ensino e aprendizagem característicos, e o professor tem um papel fundamental sob esta estrutura formativa.

Passou a ser reconhecida e denominada como uma modalidade de ensino a partir da metade da década de 1990. Seu histórico é reforçado por meio do inciso I do artigo 208 da constituição de 1988 e pela Lei de Diretrizes e Bases da Educação (LBD) n 9394/96 de 20 de dezembro de 1996 - Título V, Capítulo II, Seção V, dos quais atribuem ao Estado, o dever de garantir a todos os brasileiros o direito à educação incluindo aqueles que não tiveram acesso à escolarização na idade oportuna, sendo eles jovens, adultos ou idosos.

É possível observar um aumento significativo de pesquisas e produções acadêmicas sobre a modalidade no Brasil. Atualmente, desenvolvemos para o programa de PósGraduação/ Mestrado em Educação da Universidade Federal de Ouro Preto a pesquisa com o título "A prática docente na EJA multisseriada". A Multisseriação tratada nesse trabalho é compreendida como uma forma de organização do ensino que mantém em uma única sala de aula, em uma única Classe, alunos matriculados em períodos diferentes, diante da mediação de um único professor.

Para dar início a essa pesquisa de Mestrado (ainda em andamento), foi necessário mapear as produções acadêmicas desenvolvidas sobre Classes Multisseriadas na EJA, para assim, traçarmos um panorama do que já foi produzido sobre a temática entre os anos de 2011 a 2017 no país. Nos baseamos nas ideias de Romanowski; Ens (2006) e denominamos o mapeamento aqui realizado como uma pesquisa do tipo Estado do Conhecimento. Romanowski; Ens (2006, p. 39-40), afirmam que há uma distinção entre os dois tipos de investigação, isto é, o Estado da Arte e o Estado do conhecimento. Segundo as autoras, o Estado da Arte exige do pesquisador investigações mais abrangentes, detalhistas, enquanto o Estado do Conhecimento exige do pesquisador investigações precisas sobre o tema, mas que não exijam tantos detalhamentos e abrangências.

Os resultados dessa pesquisa bibliográfica estão, portanto, apresentados aqui neste trabalho, com o intuito de mostrar a relevância do tema pesquisado e principalmente, a sua 
relevância no contexto da Educação de Jovens e Adultos no país e fazem parte do corpo teórico da pesquisa de Mestrado (em Andamento), referenciada no início do trabalho.

\section{A multisseriação na EJA nos anos iniciais do Ensino Fundamental}

Para a localização das obras aqui apresentadas, foram organizadas quatro etapas investigativas. Na primeira etapa, as buscas se deram em quatro sites com renome acadêmico. A segunda etapa houve a seleção de obras abrangendo um panorama temporal mais geral especificamente no Catálogo de Teses e Dissertações da Capes (Coordenação de Aperfeiçoamento de Pessoal de Nível Superior). Na terceira etapa, analisamos referenciais teóricos de obras cujos temas se aproximavam da temática investigada e a quarta etapa foram realizadas pesquisas mais aprofundadas utilizando outros descritores.

Como vimos anteriormente, a EJA passou a ser reconhecida e denominada como uma modalidade de ensino a partir da metade da década de 1990. Trata-se de uma modalidade com características próprias, metodologias, planejamentos e atividades específicas, constituída por processos de ensino e aprendizagem característicos, e o professor tem um papel fundamental nesta estrutura formativa.

Nos últimos anos, é possível observar um aumento significativo de pesquisas e produções acadêmicas sobre a EJA no Brasil. Nesta seção, vamos nos basear nas ideias de Romanowski e Ens (2006) e denominar o mapeamento bibliográfico aqui realizado como uma pesquisa do tipo Estado do Conhecimento. Há uma diferença entre os dois tipos de investigação (Estado da Arte e Estado do Conhecimento) utilizados em pesquisas acadêmicas e justificamos a escolha pelo termo Estado do Conhecimento fundamentada nas palavras dos autores. Para Romanowski e Ens (2006), o Estado da Arte exige do pesquisador investigações mais abrangentes, detalhistas, enquanto o Estado do Conhecimento exige do pesquisador investigações precisas sobre o tema, mas que não exijam envolvem detalhamentos e abrangências.

Para realizar um "estado da arte" [...] não basta apenas estudar os resumos de dissertações e tese, são necessários estudos sobre as produções e congressos na área, estudos sobre as publicações em periódicos na área. O estudo que aborda apenas um setor das publicações sobre o tema estudado vem sendo denominado de "estado do conhecimento" (ROMANOWSKI; ENS, 2006, p. 39-40).

Considerando o mapeamento dos referenciais teóricos e bibliográficos como a fase de iniciação desta investigação, após a definição do que pretendíamos investigar, traçamos um panorama temporal correspondendo à busca e às análises de obras cujas publicações se deram nos últimos sete anos, entre 2010 e 2016. Em seguida, traçamos um 
novo panorama. Dessa vez, não delimitamos o ano de publicação, mas utilizamos, como tempo limite, as publicações feitas no ano de 2017.

Assim, a seleção das obras apresentadas foi realizada com base em três etapas: 1) Seleção de obras em quatro sites com renome acadêmico;2) Seleção de obras abrangendo um panorama temporal mais geral no site da CAPES; 3 ) Análise de referenciais teóricos de obras cujos temas se aproximavam ao objeto investigado.

\section{Primeira etapa investigativa}

Na primeira etapa, escolhemos quatro sites importantes de pesquisas e produções acadêmicas. O primeiro refere-se ao site da Coordenação de Aperfeiçoamento de Pessoal do Nível Superior (CAPES), por meio do acesso ao Banco de Dados e ao Catálogo de Teses e Dissertações; o segundo foi o site da Biblioteca Digital Brasileira de Teses e Dissertações (BDTD), cujo acesso se deu por meio do site do Instituto Brasileiro de Informação em Ciência e Tecnologia (IBICT); o terceiro é o site da Associação Nacional de Pós-graduação e Pesquisa em Educação (ANPED), cujo acesso se dirigiu especificamente ao Grupo de Trabalho sobre Educação de Jovens e Adultos (GT 18); e o quarto site pesquisado foi o Scientific Electronic Library Online (SciELO).

Para o levantamento das primeiras fontes documentais, foi utilizado um descritorchave: classes multisseriadas EJA. Para a seleção dos documentos, delineamos três etapas: primeiro, buscamos analisar a área de conhecimento em que as publicações estavam inseridas e, posteriormente, seus títulos. Assim, selecionamos alguns trabalhos e registramos, em um quadro, dados sobre o site em que foram encontrados, bem como o título, os nomes dos autores e o ano de publicação. O próximo passo foi a realização da leitura e análise dos resumos desses trabalhos. Por último, as obras que mais se encaixavam à temática investigada foram lidas por completo e somadas ao referencial teórico da pesquisa. A seguir, apresentamos os resultados obtidos. 
Quadro 1 - Panorama geral por fonte pesquisada 2010 a 2016

\begin{tabular}{c|c|c|c}
\hline Fontes & Descritor utilizado & Total de trabalhos & $\begin{array}{c}\text { Trabalhos que } \\
\text { abordam o tema }\end{array}$ \\
\hline CAPES & Classes multisseriadas EJA & 18 & 0 \\
\hline BDTD & Classes multisseriadas EJA & 0 & 0 \\
\hline ANPED & Classes multisseriadas EJA & 0 & 0 \\
\hline SciELO & Classes multisseriadas EJA & 5 & 0 \\
\hline TOTAL & & 23 & 0 \\
\hline
\end{tabular}

\section{Fonte: Elaborado pela autora}

A primeira fonte documental investigada foi o Catálogo de Teses e Dissertações disponibilizado no site da CAPES. Por meio das buscas realizadas nesse catálogo, conseguimos um número significativo de registros em relação às outras fontes de pesquisa.

Para esta investigação, utilizamos como descritor a expressão: Classes Multisseriadas EJA. Aplicamos os filtros necessários e obtivemos, no total, 1.446 trabalhos. Analisando, em cada trabalho, o tema, a área de conhecimento e o título, foi possível selecionar, desse número total, 18 trabalhos. No entanto, a partir da análise e da leitura dos seus resumos, nenhum deles trazia discussões sobre a temática investigada. Assim, consideramos que nenhum resultado foi obtido ao analisarmos as produções compreendidas entre os anos de 2011 e 2016, no site da CAPES.

Nos demais sites (BDTD, ANPED e SciELO), também não foi possível localizar produções sobre classes multisseriadas na EJA. No SciELO, selecionamos cinco trabalhos pelo título, mas, a partir da leitura dos seus resumos, nenhum tratava do objeto de estudo aqui investigado. As investigações no site da ANPED percorreram suas seis últimas reuniões, ou seja, da 32ª Reunião (em outubro de 2009) até a 37 ${ }^{\text {a }}$ Reunião (em outubro de 2015). Nelas, nenhum trabalho foi encontrado, de acordo com o panorama investigativo traçado para esta etapa.

Segunda etapa investigativa

Diante do primeiro resultado negativo, referenciado acima, traçamos uma segunda etapa investigativa. Nesta, ainda no site da CAPES, procuramos por obras mais recentes, mas não delimitamos um panorama temporal das publicações, como na etapa anterior. Assim, foi possível localizar duas pesquisas/produções que tratam sobre classes multisseriadas na EJA. 


\section{Quadro 2 - Trabalhos identificados no Catálogo de Teses e Dissertações (CAPES)}

\begin{tabular}{c|c|c|c|c|c}
\hline & Título & Nível & Ano & Instituição & UF \\
\hline $\mathbf{1}$ & $\begin{array}{c}\text { Educação de Jovens e } \\
\text { Adultos: o desafio das } \\
\text { classes multisseriadas }\end{array}$ & Mestrado & 2003 & $\begin{array}{c}\text { Universidade Metodista } \\
\text { de São Paulo }\end{array}$ & SP \\
\hline & $\begin{array}{c}\text { Aprendizagem distraída e } \\
\text { multisseriação: novos } \\
\text { caminhos para a Educação } \\
\text { de Jovens e Adultos }\end{array}$ & Mestrado & 2017 & Colégio Pedro II & RJ \\
\hline
\end{tabular}

Fonte: Elaborado pela autora

A primeira produção identificada foi desenvolvida por Ana Cristina Silva da Rosa, em 2003, no Programa de Pós-graduação em Educação (Mestrado em Educação), da Universidade Metodista de São Paulo, e foi intitulada Educação de Jovens e Adultos: o desafio das classes multisseriadas, sob orientação da Prof ${ }^{a}$. Dra‥ Marília Claret Geraes Duran.

A pesquisa desenvolvida por Rosa (2003) procurou investigar e compreender como se dava a gestão das aulas em classes multisseriadas na EJA. O termo gestão, trazido pela autora pauta-se na concepção de Gauthier (2001 apud ROSA, 2003), e se refere à necessidade de o professor saber gerir o seu trabalho para um grupo de alunos. O estudo trata de uma pesquisa de abordagem qualitativa, em que foram entrevistados cinco professores por meio de entrevistas do tipo não-diretiva/semi-estruturada, e também foi realizada a observação das práticas desses profissionais.

Em um artigo produzido em 2008, sobre a pesquisa desenvolvida no ano de 2003, a pesquisadora deixa claro que, naquela época, haviam poucas produções sobre classes multisseriadas no Brasil:

Discutir esta forma de organização escolar é um grande desafio, principalmente porque em levantamento bibliográfico se observa que pouco foi produzido sobre este campo de atuação: as classes multisseriadas. As poucas pesquisas ou artigos publicados detêm-se em discutir esta maneira de organização escolar nas escolas rurais (ROSA, 2008, p. 224).

A pesquisadora entrevistou, portanto, cinco professores e observou a prática de cada um dos cinco profissionais durante cinco dias letivos, do início ao final das aulas. Como resultado da pesquisa, Rosa (2003) descreve que os professores se preocupavam muito em buscar diferentes alternativas para conseguir atender a todos os alunos, ao apontar para os desafios relatados por cada professor ao atuar nas classes multisseriadas. Ao final da sua dissertação, assinalou alguns princípios básicos que devem ser considerados para a 
formação de todo e qualquer educador, especialmente os educadores que atuam na EJA, no contexto das classes multisseriadas.

A segunda obra encontrada é de autoria de Gabriel Moreira Beraldi (2017), por meio do Programa de Pós-graduação, Pesquisa, Extensão e Cultura (Mestrado Profissional em Práticas de Educação Básica), do Colégio Pedro II, no Rio de Janeiro-MG.

Intitulada $A$ aprendizagem distraída e multisseriação: novos caminhos para a Educação de Jovens e Adultos, a pesquisa esteve sob orientação do Prof. Dr. Francisco Roberto Pinto Mattos e procurou investigar a questão da multisseriação na EJA, não como um desafio, mas como uma possibilidade. Segundo o autor da pesquisa, o trabalho procura refletir sobre a EJA multisseriada e sobre a necessidade de lançar mão de inúmeros recursos lúdicos disponíveis para alcançar um ensino significativo na aprendizagem. Seu objetivo é fazer com que professores reflitam sobre as suas práticas docentes para que possam desempenhar trabalhos significativos a aprendizagem dos seus educandos.

De acordo com o autor, os docentes que aceitam trabalhar em classes multisseriadas devem estar abertos à aquisição constante de conhecimentos, para receberem uma formação adequada e, assim, lidar com a realidade a que estarão submetidos, pois o trabalho na EJA exige planejamento, conhecimento sobre a modalidade e muito empenho do profissional.

Assim, como afirma Beraldi (2017, p. 17),

a multisseriação, em última instância, propõe uma metodologia que visa superar o paradigma liberal tradicional através da desfragmentação dos conhecimentos, transformando a escola em um ambiente de inclusão social e educacional. Dessa forma, a EJA precisa propor ações que de fato sejam significativas ao estudante, impedindo sua evasão e preparando-o para os desafios do dia-a-dia.

Deste modo, tanto a obra de Rosa (2003), quanto a obra de Beraldi (2017), serão importantíssimas para a construção do referencial teórico neste trabalho, pois percebemos a multisseriação na EJA como um tema que precisa ainda ser investigado, tendo em vista o mapeamento das produções acadêmicas publicadas até o momento sobre o objeto de estudo. Foi possível constatar que não há um número significativo de publicações sobre essa temática no Brasil e, assim, compreender como se dá o processo de ensino em classes multisseriadas na EJA nos Anos Iniciais do Ensino Fundamental passa a ser um desafio para este trabalho.

\section{Terceira etapa investigativa}

Durante as buscas, verificamos que a maioria das produções sobre classes multisseriadas situava-se em trabalhos sobre a Educação do Campo. Assim, procuramos um novo caminho para entendermos mais sobre as classes multisseriadas, analisando obras 
publicadas sobre sua organização de ensino na Educação do Campo, e traçamos, portanto, uma terceira etapa para encontrar mais referências significativas à pesquisa e ao estudo.

A primeira iniciativa nesse sentido foi acessar novamente o site da ANPED. Nele, selecionamos o GT 03, que trata dos Movimentos sociais, sujeitos e processos educativos, o GT 08, que trata da Formação de professores, e o GT 06, sobre Educação popular. Analisamos os trabalhos dos três GTs a partir da 30 Reunião Nacional, realizada em Caxambu-MG, em outubro de 2007, até a 37ª Reunião Nacional, realizada em FlorianópolisSC, em outubro de 2015. Por meio dessa primeira busca, foi possível localizar dois trabalhos, um no GT 03 e outro no GT 08.

\begin{tabular}{|c|c|c|c|c|c|}
\hline \multicolumn{6}{|c|}{ Quadro 3 - Trabalhos localizados no GT 03 e GT 08} \\
\hline & Título & Modalidade & Reunião & GT & Instituição \\
\hline 1 & $\begin{array}{l}\text { Escola rural } \\
\text { multisseriada: } \\
\text { contexto e } \\
\text { perspectivas no } \\
\text { município de } \\
\text { Urubici-SC }\end{array}$ & $\begin{array}{l}\text { Trabalho } \\
\text { completo }\end{array}$ & $\begin{array}{c}35^{\underline{a}} \\
\text { Reunião }\end{array}$ & $\begin{array}{c}03 \\
\text { Movimentos } \\
\text { sociais, } \\
\text { sujeitos e } \\
\text { Processos } \\
\text { educativos }\end{array}$ & $\begin{array}{c}\text { UFSC } \\
\text { Universidade } \\
\text { de Santa } \\
\text { Catarina }\end{array}$ \\
\hline 2 & $\begin{array}{l}\text { Ação/formação } \\
\text { do professor das } \\
\text { escolas multisse- } \\
\text { riadas no municí- } \\
\text { pio de Igarapé- } \\
\text { açu-PA: retratos } \\
\text { de uma realidade }\end{array}$ & Pôster & $\begin{array}{c}36^{\underline{a}} \\
\text { Reunião }\end{array}$ & $\begin{array}{c}08 \\
\text { Formação } \\
\text { de } \\
\text { professores }\end{array}$ & $\begin{array}{c}\text { UEPA } \\
\text { Universidade } \\
\text { do Estado do } \\
\text { Pará }\end{array}$ \\
\hline
\end{tabular}

Fonte: Elaborado pela autora

Em seguida, realizamos uma busca mais profunda no site e encontramos trabaIhos em outros GTs. A seguir, apresentamos os demais trabalhos localizados no site da ANPED. 


\begin{tabular}{|c|c|c|c|c|c|}
\hline & Título & Tipo & Reunião & GT & Instituição \\
\hline 1 & $\begin{array}{c}\text { Práticas de alfabetização } \\
\text { em turmas } \\
\text { multisseriadas: } \\
\text { estratégias docentes } \\
\text { para lidar com a } \\
\text { heterogeneidade de } \\
\text { aprendizagens }\end{array}$ & $\begin{array}{l}\text { Trabalho } \\
\text { completo }\end{array}$ & $\begin{array}{c}37^{\mathrm{a}} \\
\text { Reunião }\end{array}$ & $\begin{array}{c}10 \\
\text { Alfabetização } \\
\text { Leitura e } \\
\text { Escrita }\end{array}$ & $\begin{array}{l}\text { UFPE } \\
\text { Universidade } \\
\text { Federal de } \\
\text { Pernambuco }\end{array}$ \\
\hline 2 & $\begin{array}{c}\text { A realidade das escolas } \\
\text { multisseriadas frente às } \\
\text { conquistas na legislação } \\
\text { educacional }\end{array}$ & Pôster & $\begin{array}{c}29^{a} \\
\text { Reunião }\end{array}$ & $\begin{array}{c}13 \\
\text { Educação } \\
\text { Fundamental }\end{array}$ & $\begin{array}{l}\text { UFPA } \\
\text { Universidade } \\
\text { Federal do } \\
\text { Pará }\end{array}$ \\
\hline 3 & $\begin{array}{c}\text { As formas de } \\
\text { institucionalização e } \\
\text { organização do tempo } \\
\text { Escolar no ensino } \\
\text { fundamental: tempos e } \\
\text { ritmos em escolas } \\
\text { com classes } \\
\text { multisseriadas da llha de } \\
\text { Maré }\end{array}$ & $\begin{array}{l}\text { Trabalho } \\
\text { completo }\end{array}$ & $\begin{array}{c}35^{\underline{a}} \\
\text { Reunião }\end{array}$ & $\begin{array}{c}13 \\
\text { Educação } \\
\text { Fundamental }\end{array}$ & $\begin{array}{l}\text { UNEB } \\
\text { Universidade } \\
\text { do Estado da } \\
\text { Bahia }\end{array}$ \\
\hline 4 & $\begin{array}{c}\text { Educação rural e as } \\
\text { salas multisseriadas: } \\
\text { uma reflexão } \\
\text { Sobre as políticas } \\
\text { públicas para esse } \\
\text { contexto }\end{array}$ & Pôster & $\begin{array}{c}37^{\mathrm{a}} \\
\text { Reunião }\end{array}$ & $\begin{array}{c}14 \\
\text { Sociologia da } \\
\text { Educação }\end{array}$ & $\begin{array}{l}\text { UFJF } \\
\text { Universidade } \\
\text { Federal de } \\
\text { Juiz de Fora }\end{array}$ \\
\hline
\end{tabular}

Fonte: Elaborado pela autora

A partir da análise desse material, verificamos que vários deles citavam obras produzidas ou organizadas por Salomão Mufarrej Hage.

Verificamos também que um dos trabalhos selecionados e identificados no quadro acima como o trabalho $\mathrm{n}^{\circ} .2$, intitulado $A$ realidade das escolas multisseriadas frente às conquistas na legislação educacional, é de autoria do pesquisador.

Por meio dessas informações, passamos a procurar pelos trabalhos produzidos por esse pesquisador. Hage possui doutorado em Educação, pela Pontifícia Universidade Católica de São Paulo (2000), é professor do Instituto de Ciências da Educação da Universidade Federal do Pará e docente do Programa de Pós-graduação em Educação e do Programa de Linguagens e Saberes da Amazônia. Recentemente, tem atuado em um grupo 
de pesquisa na Universidade Federal do Pará, no qual são realizados estudos sobre as escolas multisseriadas do campo.

As produções de Hage sobre as classes multisseriadas, mesmo baseadas em estudos sobre a Educação do Campo, serão referenciadas teoricamente neste trabalho para falarmos um pouco mais do ensino multisseriado no Brasil. Localizamos uma obra cujo título é Escola de Direito - reinventando a escola multissseriada, organizada pelo pesquisador e por Maria Isabel Antunes Rocha, publicada em 2010. O livro traz várias narrativas sobre a Educação do Campo e importantes trabalhos sobre as classes multisseridas nesses ambientes.

\section{Quarta etapa investigativa}

Em uma pesquisa mais aprofundada pelo site SciELO, localizamos a obra Escolas multisseriadas: a experiência internacional e reflexões para o caso brasileiro, escrita por Cláudia da Mota Darós Parente, publicada em 2014 e que aborda as escolas multisseriadas do campo.

Parente (2014) apresenta um estudo sobre a multisseriação com base em uma literatura internacional, analisando pesquisas e experiências sobre essa organização do ensino em vários países. Por meio de sua obra, é possível compreender que a multisseriação está presente em todo o mundo.

$\mathrm{Na}$ obra, a autora traz o termo "escola multisseriada" como uma tradução de "multigrade schoof', mesmo sabendo que as experiências de cada país podem carregar concepções e práticas pedagógicas diferenciadas. Para a autora, a multisseriação surgiu a partir da democratização da educação. Ou seja, ao possibilitar o acesso à educação para todos, surgiram inúmeras demandas das populações, tornando a multisseriação o melhor caminho para sua oferta e acesso, principalmente em localidades distantes e isoladas, como é o caso da multisseriação na Educação do Campo. "A multisseriação existe tanto em países desenvolvidos como em países em desenvolvimento, tanto em zonas rurais, como em zonas urbanas. Porém, são estreitos seus vínculos com o campo e com as regiões menos povoadas" (PARENTE, 2014, p. 63).

Cardoso e Jacomeli (2010, p. 1), na obra Considerações sobre as escolas multisseriadas: Estado da Arte, afirmam que elas "são escolas organizadas em uma sala única, na qual se reúnem alunos pertencentes, geralmente às quatro séries iniciais do Ensino Fundamental, sob a regência de um único professor". As autoras descrevem que, durante as 
buscas realizadas, foram encontrados artigos e dissertações que versam sobre temas ligados às escolas multisseriadas, como: educação para o campo, escolas unidocentes e classes multisseriadas. Para a realização dessas buscas, ambas utilizaram as seguintes palavraschave: escola/s multisseriada/s, classe/s multisseriada/s, classe/s multiseriada/s, bisseriada/s, ensino multisseriado e sala/s multisseriada/s. De acordo com as autoras, foi a partir da década de 1990 que as produções científicas sobre as escolas multisseriadas começaram a se efetivar.

Assim como Cardoso e Jacomeli (2010), em nossas buscas, foram utilizados e encontrados diferentes termos relacionados à temática da multisseriação: escolas multisseriadas, turmas multisseriadas, classes multisseriadas, escolas unidocentes, turmas unidocentes, escolas isoladas, dentre outros. Ressalta-se que grande parte desses trabalhos situam-se em estudos sobre a Educação do Campo.

Assim, não podemos negar que o berço da multisseriação, no Brasil, encontra-se na Educação do Campo. Confirmamos isto a partir de Santos e Moura (2010), que afirmam que as classes multisseriadas ou unidocentes não são coisas do passado, mas uma realidade comum observada, em sua maioria, em espaços rurais, nas escolas do campo.

A legislação da Educação do Campo reconhece e regulamenta o funcionamento das escolas multisseriadas nesses contextos, como o Art. 10 da Resolução nํ. 2, de 28 de abril de 2008, que trata das Diretrizes Operacionais para a Educação Básica nas Escolas do Campo. O Artigo garante, em seu inciso $2^{\circ}$, que as escolas multisseriadas devem ter uma estrutura física adequada, recursos, apoio pedagógico e profissionais capacitados para atingirem uma educação de qualidade, com base no padrão educacional nacional.

No entanto, nas legislações analisadas até o momento sobre a EJA, nada se fala sobre a organização do ensino multisseriado. Percebemos, portanto, que propor investigações sobre o ensino multisseriado na EJA é uma iniciativa importante, pois a temática não tem sido contemplada em pesquisas recentes do campo educacional. Existem muitas pesquisas realizadas e ainda em desenvolvimento sobre a EJA, mas, com base nas informações apresentadas, é preciso investigar, pesquisar, produzir e publicar sobre os processos de ensino, a prática docente e sobre várias outras demandas que a EJA ainda necessita. Nesse sentido, retomamos nossa proposta de procurar proporcionar, aos professores dessa modalidade que atuam na Região dos Inconfidentes e em outras partes do país, a possibilidade de refletirem mais sobre EJA, sobre a multisseriação e sobre a sua prática docente. 


\section{CONSIDERAÇÕES FINAIS}

Segundo Parente (2014), as escolas multisseriadas surgiram da necessidade em atender a populações excluídas ao longo da história, em um momento em que a democratização da educação, isto é, o acesso à educação passou a ser um direito de todos os cidadãos no mundo. A partir da década de 1990, os estudos sobre a Multisseriação começaram a difundir tanto no cenário nacional quanto em cenários internacionais, em países desenvolvidos e não desenvolvidos.

Por meio do Estado do Conhecimento aqui apresentado, constatamos que as produções e os estudos até então realizados sobre a EJA multisseriada são insuficientes em relação às demandas e às urgências que envolvem a temática e que a maior parte dos trabalhos encontrados sobre a multisseriação se deslocam para a modalidade da educação do campo. Segundo o Art. 23 da LDB/96, a Educação Básica poderá se organizar de acordo com a necessidade do processo educativo, isto é,

Art. 23. A educação básica poderá organizar-se em séries anuais, períodos semestrais, ciclos, alternância regular de períodos de estudos, grupos não seriados, com base na idade, na competência e em outros critérios, ou por forma diversa de organização, sempre que 0 interesse do processo de aprendizagem assim 0 recomendar (BRASIL, 2017, p. 17).

A Multisseriação é uma organização do ensino legal, garantida por Lei. Esta Lei garante que os sistemas de ensino podem se organizar de acordo com a necessidade, da realidade do processo educativo. Assim, a organização de turmas na EJA com alunos matriculados em diferentes níveis de aprendizagem, frequentando uma única sala de aula com a presença de um único professor mediador é realidade da Região pesquisada e, o que se revela na pesquisa de Mestrado, é que essa organização do ensino envolve inúmeras questões de cunho político e econômico por parte dos municípios investigados na pesquisa, responsáveis pela oferta da modalidade nos anos inicias do Ensino Fundamental.

Sabemos que a Educação de Jovens e Adultos é uma modalidade que carrega consigo a heterogeneidade, a singularidade das turmas e dos sujeitos que a frequentam e exige um trabalho diferenciado por parte do professor diante dessas especificidades, principalmente quando o trabalho é realizado nos anos iniciais do Ensino Fundamental, fase em que os alunos estão passando pelo período de alfabetização. Mas além das especificidades próprias da modalidade, há a multisseriação nos anos iniciais do Ensino Fundamental. Portanto, o uso do termo Classe Multisseriada é justificado neste trabalho e na pesquisa de Mestrado, para caracterizar essa organização do ensino, aqui caracterizada, ministrada em escolas que oferecem EJA. 
Em sua obra, Hage (2011) revela a angústia de professores que atuam em espaços escolares que assumiram a proposta da multissérie em escolas da educação do campo. Segundo o autor, esses professores se sentem ansiosos para realizar um bom trabalho, mas, ao mesmo tempo, se sentem confusos, pois necessitam de um apoio pedagógico para lidar com a heterogeneidade das turmas, que não existe.

\begin{abstract}
Identificamos ainda nos depoimentos, as angústias sentidas pelos professores ao conduzir o processo pedagógico justamente porque assumem a "proposta de multissérie", enquanto "junção de várias séries ao mesmo tempo e num mesmo espaço", passando a elaborar tantos planos de ensino e estratégias de avaliação da aprendizagem diferenciados quanto forem as séries presentes em sua turma. Como resultado, os professores se sentem ansiosos ao pretender realizar o trabalho da melhor forma possível, e ao mesmo tempo perdidos, carecendo de apoio para organizar o tempo escolar, numa situação em que atua em várias séries concomitantemente (HAGE, 2011, p. 3).
\end{abstract}

Diante das falas do autor, a questão da multisseriação provoca dúvidas, angústias e insegurança na maioria dos professores entrevistados por ele. Mas, dando continuidade a leitura de sua obra, Hage (2011) nos remete também a ideia de que pesquisar, estudar, compreender mais sobre a organização do ensino multisseriado nas escolas brasileiras, não só em escolas do campo é de suma importância, pois é um campo rico de saberes. Um campo rico, que muitas vezes, é visto como um empasse, um desafio.

Existem muitas pesquisas realizadas sobre a EJA, mas, compreendemos que ainda é preciso investigar, pesquisar, produzir e publicar sobre os processos de ensino e aprendizagem. Pesquisar sobre a formação dos educadores que atuam nesta modalidade e sobre várias outras demandas que a Educação de Jovens e Adultos apresenta no dia-a-dia da escola.

Grande parte das políticas educacionais para a EJA na Região dos Inconfidentes nos anos finais e no ensino Médio seguem os vieses das regulamentações da Educação do estado de Minas Gerais. Mas, a organização e o funcionamento da modalidade EJA nos anos iniciais do Ensino Fundamental nas escolas públicas/municipais é responsabilidade dos municípios. Eles têm autonomia para problematizar a multisseriação na EJA e ofertar um ensino de qualidade aos seus alunos.

Portanto, o trabalho em desenvolvimento para o programa de Mestrado da UFOP, traz inúmeras implicações para o campo investigativo da Educação de Jovens e Adultos. Mesmo com todo o seu aparato legal, a Educação de Jovens e Adultos brasileira ainda precisa de grandes ajustes, sejam em suas políticas públicas já instauradas, seja em seu currículo, no preparo dos profissionais que atuam ou que irão atuar nos espaços educacionais, dentre outras questões. Destacamos aqui, portanto, a urgência em continuar pensando a EJA em 
suas singularidades, em suas particularidades, como uma modalidade de ensino que necessita da efetivação/reparo das suas bases legais, para a promoção e garantia de uma educação de qualidade aos sujeitos que nela frequentam ou irão frequentar. Todo o cidadão, tem direito a educação. Assim, problematizar a Multisseriação na EJA é um tema de suma importância para a modalidade, pois é uma realidade nos municípios investigados, e envolve sérias questões de cunho político, econômico, social, pedagógico, dentre várias outras questões e, o que nós pesquisadores buscamos, é a real garantia da oferta de uma educação de Direito, de uma educação que de fato seja significativa e que tenha qualidade, à todos os sujeitos da modalidade.

\section{REFERÊNCIAS}

ANTUNES-ROCHA, Maria Isabel; HAGE, Salomão Mufarrej (orgs.). Escola de direito: reinventando a escola multisseriada. Belo Horizonte: Autêntica, 2010. 424 p.

BERALDI, Gabriel Moreira. Aprendizagem distraída e multisseriação: novos caminhos para a Educação de Jovens e Adultos. 2017. 166 p. Dissertação (Mestrado profissional em Educação) - Colégio Pedro II, Rio de Janeiro, 2017.

BRASIL. Constituição Federal de (1998). Brasília, DF: Senado, 1998.

BRASIL. Lei de Diretrizes e Bases da Educação Nacional. Lei no 9.394/96. Brasília, 20 de dez. de 1996.

BRASIL. Diretrizes Curriculares Nacionais Gerais para a Educação Básica. Brasília: Conselho Nacional de Educação, 2013.

CARDOSO, Maria Angélica; JACOMELI, Maria Regina Martins. Considerações sobre as escolas multisseriadas: estado da arte. Educere et Educare, Unioeste Campus Cascavel, Paraná, v. 5, n. 9, p. 267-290, jan./jun. 2010.

HAGE, S. A. M. A multissérie em pauta: para transgredir o paradigma seriado nas escolas do campo. In: MUNARIM, A.; BELTRAME, S.; CONDE, S.; PEIXER, Z. (orgs.). Educação do Campo: políticas públicas, territorialidades e práticas pedagógicas. v. 1. Florianópolis: Editora Insular Ltda., 2011, p. 123-144.

MINAS GERAIS. Resolução SEE no. 2.843, de 13 de janeiro 2016. Minas Gerais: Secretaria de Estado de Educação de Minas Gerais. 2016. 4 p. 
PARENTE, Cláudia da Mota Darós. Escolas multisseriadas: a experiência internacional e reflexões para o caso brasileiro. Ensaio: aval.pol.públ.Educ. [online], Rio de Janeiro, v. 22, n. 82, p. 57-88, jan./mar. 2014.

ROMANOWSKI, Joana Paulin; ENS, Romilda Teodora. As pesquisas denominadas do tipo Estado da Arte em Educação. Revista Diálogo Educacional, Pontifícia Universidade Católica do Paraná, v. 6, n. 19, p. 37-50, 2006.

ROSA, Ana Cristina Silva da. Educação de jovens e adultos: o desafio das classes multisseriadas. 2003. 150 p. Dissertação (Mestrado em Educação) - Universidade Metodista de São Paulo, São Bernardo do Campo, 2003.

SANTOS, Fábio Josué Sousa dos; MOURA, Terciana Vidal. Políticas educacionais, modernização pedagógica e racionalização do trabalho docente: problematizando as representações negativas sobre as classes multisseriadas. In: ANTUNES-ROCHA, Maria Isabel; HAGE, Salomão Mufarrej (orgs.). Escola de direito: reinventando a escola multisseriada. Belo Horizonte: Autêntica, 2010, p. 35-48. (Coleção Caminhos da Educação do Campo; v. 2) 